\title{
IGNITION PROBABILITY AND LEAN IGNITION BEHAVIOUR OF A SWIRLED PREMIXED BLUFF BODY STABILISED ANNULAR COMBUSTOR
}

\author{
Roberto Ciardiello ${ }^{1, *}$, Rohit S. Pathania ${ }^{1}$, Patton M. Allison ${ }^{2}$, Pedro M. de Oliveira ${ }^{1}$, Epaminondas Mastorakos ${ }^{1}$ \\ ${ }^{1}$ University of Cambridge, Cambridge, UK \\ ${ }^{2}$ Michigan State University, East Lansing, Michigan, USA
}

\section{ABSTRACT}

An experimental investigation was performed in a premixed annular combustor equipped with multiple swirl, bluff body burners to assess the ignition probability and to provide insights into the mechanisms of failure and of successful propagation. The experiments are done at conditions that are close to the lean blowoff limit ( $L B O)$ and hence the ignition is difficult and close to the limiting condition when ignition is not possible. Two configurations were employed, with 12 and 18 burners, the mixture velocity was varied between 10 and $30 \mathrm{~m} / \mathrm{s}$, and the equivalence ratio $(\phi)$ between 0.58 and 0.68. Ignition was initiated by a sequence of sparks (2 mm gap, 10 sparks of $10 \mathrm{~ms}$ each) and "ignition" is defined as successful ignition of the whole annular combustor. The mechanism of success and failure of the ignition process and the flame propagation patterns were investigated via high-speed imaging $(10 \mathrm{kHz})$ of $\mathrm{OH}^{*}$ chemiluminescence. The lean ignition limits were evaluated and compared to the lean blow-off limits, finding the 12-burner configuration is more stable than the 18burner. It was found that failure is linked to the trapping of the initial flame kernel inside the inner recirculation zone (IRZ) of a single burner adjacent to the spark, followed by localised quenching on the bluff body probably due to heat losses. In contrast, for a successful ignition, it was necessary for the flame kernel to propagate to the adjacent burner or for a flame pocket to be convected downstream in the chamber to grow and start propagating upwards. Finally, the ignition probability $\left(P_{i g n}\right)$ was obtained for different spark locations. It was found that sparking inside the recirculation zone resulted in $P_{i g n} \sim 0$ for most conditions, while $P_{\text {ign }}$ increased moving the spark away from the bluff-body or placing it between two burners and peaked to $P_{i g n} \sim 1$ when the spark was located downstream in the combustion chamber, where the velocities are lower and the turbulence less intense. The results provide information on the most favourable conditions for achieving ignition in a complex multi-burner geometry and could help the design and optimisation of realistic gas turbine

*Corresponding author: rc733@cam.ac.uk combustors.

Keywords: Ignition probability, annular combustor, premixed turbulent flames, stability limits

\section{INTRODUCTION}

Lean premixed combustion is currently being considered in gas turbine combustors as a possible way to reduce the formation of harmful pollutants, namely $\mathrm{NO}_{X}$ and soot $[1,2]$. However, lean flames are more prone to thermoacoustic instabilities and lean blow-off (LBO). As a result, relight and flame stabilisation are important to consider for lean combustion.

Ignition is achieved by local deposition of a source of energy, usually by employing a spark or a laser [3]. The ignition transient can be divided in four phases [4, 5]: formation of a flame kernel (i), flame growth (ii), flame stabilisation over a single burner (iii) and flame propagation from one burner to the adjacent one to ignite the entire combustor (iv). The fourth phase (known as light-round) can only happen in case of a multi-burner configuration, like the annular combustor. Gas turbine combustors usually employ such complex geometries [1].

Ignition and light-round have been experimentally investigated in conditions not too close to LBO in premixed [6-8], non-premixed [9] and spray [10, 11] annular combustors. It was found that the light-round time decreases when increasing bulk velocity and equivalence ratio, as a result in the increase in the turbulent flame speed. The propagation mechanism appeared to follow a "sawtooth" pattern, with flame arches propagating in the azimuthal direction from burner-to-burner and upstream to ignite each individual burner. However, all these investigations were performed at conditions far from LBO, where the flame could find favourable conditions to propagate along the chamber. In contrast, this work will focus on ignition probability and the mechanism controlling successful and failed ignition events for very lean mixtures in a premixed annular combustor, at conditions close to LBO.

The ignition probability can be defined as the number of 
successful ignition events divided by the total number of tests performed [4]. Earlier studies in non-premixed turbulent jet flames $[12,13]$ considered as successful ignition the formation of a propagating flame kernel, focusing their attention on phase 1 of the ignition process. Later, a more comprehensive view of the ignition process has been employed, taking into account also flame propagation and stabilisation, and considering an ignition trial successful after phase 3 of the process. A series of experiments on premixed [14-16], non-premixed [4, 17-19] and spray $[5,20]$ flames were carried out on different single burner configurations, including bluff-body stabilised, swirl-stabilised and counter-flow flames. The difference between the probability of creating a kernel, $P_{\text {kernel }}$, and igniting the whole burner, $P_{i g n}$, was emphasised.

In turbulent non-premixed flames, $P_{\text {kernel }}$ and $P_{i g n}$ can be correlated with the flammability factor $F$, which represents the probability of finding a flammable mixture in a specific location. In a lifted turbulent jet flame Ahmed and Mastorakos [17] found that $P_{i g n}<F$, especially for axial locations downstream of the crossing point between the stoichiometric mixture fraction and the burner axis. Successful ignition was dependent on the local flow conditions and high local velocity was detrimental for $P_{i g n}$. In addition, spark gap, duration and energy seemed to affect the ignition process, depending on the location of the spark: shorter sparks were more effective along the jet centre-line, while longer sparks were necessary for off-axis locations. In a counter-flow non premixed flame [19], on the other hand, it was reported $P_{i g n}>F$, probably due to the convection of the spark towards nearby flammable regions. Moreover, it was found that ignition could not occur for strain levels higher than $90 \%$ of the extinction strain rate, which would contribute to explain the difference between the stability limits and the lean ignition limits.

In a non-premixed bluff body stabilised flame [18], the contour of ignition probability was found to depend on the presence of swirl. With swirl, $P_{i g n}=0$ in the inner recirculation zone (IRZ), characterised by low velocities, relatively uniform mixture and high flammability factor, due to the local quenching of the flame kernel. The most favourable spark locations were found to be regions with mixture fraction close to stoichiometry, low velocity and weak turbulent intensity, such that the flame kernel was not quenched by the high strain. Moving from non-premixed gaseous to spray, Marchione et al. [20] reported that $P_{i g n}$ was higher with the spark located in a region of negative velocity and relatively low droplet diameter. Ignition success was seen to be due to flamelets propagating upstream towards the bluff body without getting extinguished. In addition, using a multiple spark sequence instead of a single spark, it was seen that the ignition could be achieved also when sparking close the wall of the combustion chamber, with the highest probability being for a spark located at the edge of the recirculation zone.

In a premixed flame, there is flammable mixture in the entire combustion chamber. In Ref. [14] it is reported that for a bluff body stabilised premixed methane-air flame the region of higher $P_{i g n}$ is the IRZ, and reaches $100 \%$ everywhere shifting towards zero when moving away downstream of the flame and in the side recirculation zone. The effect of turbulent intensity and local strain was found to be evident only when the mixture was close to the extinction limit. Sitte et al. [15] investigated the effect of local Karlovitz number $(K a)$ and local mean velocity on the ignition transient in a similar bluff-body premixed flame, but without enclosure. It was found that two conditions were needed for maximising $P_{\text {ign }}$ : (i) low $K a$ (ii) negative mean velocity. In addition, the duration of the ignition transient increased when reducing the equivalence ratio, due to a lower flame propagation speed. An important parameter to consider for the ignition of highly turbulent flames is the stochasticity involved in the process, even for a premixed flame. In Ref. [15] a stochastic low-order ignition model was successfully applied to capture the main features of the ignition transient, in particular the $P_{i g n}$ and relationship between turbulent burning velocity and duration of the ignition process.

The work previously described focused on Phase 1 to 3 of the ignition process in single burner systems and failures were found to be dependent on the unsuccessful formation of a flame kernel (Phase 1), localised quenching of the propagating flamelet (Phase 2) or the failure in flame stabilisation (Phase 3). However, real gas turbine combustors employ complex multi-burner configurations. Thus, there is lack of information on the lean ignition transient and ignition probability when the fourth phase of flame propagation (light-round) is involved. The aim of this work is to fill this gap by carrying out an experimental investigation in a premixed annular combustor, previously employed in study on thermoacoustic instabilities [21-23], stable ignition [7] and, recently, lean blow-off [24]. Two configurations were employed, composed of 12 and 18 burners respectively, to assess the effect of inter-burner distance on the ignition transient. Focus of the investigation are the phases 2 to 4 of the ignition process, in particular flame propagation and stabilisation: the duration of the spark sequence was set to be long enough to always form a flame kernel (i.e. $P_{\text {kernel }}=1$ ). Varying spark location, mixture velocity and equivalence ratio, the $P_{i g n}$ was computed for both configurations. High-speed imaging of $\mathrm{OH}^{*}$ chemiluminescence was employed to visualise the flame growth and propagation and give insight into the mechanism of successful propagation as well as failed ignition.

In a spray gas turbine combustor it is reasonable to assume that the chamber is filled with fuel droplets prior to ignition, thus studying fully premixed gaseous flames is an idealisation of the processes occurring in a realistic engine and can shed light on the key physics behind the flame propagation. In addition, although lean premixed combustion has not been implemented in aircraft combustors yet, premixed flames are finding an increasing usage in industrial gas turbines [2]. Moreover, new technologies, such as lean premixed prevapourised (LPP) combustion [25], lean direct injection (LDI) [26] or the twin annular premixing swirler (TAPS) combustor [27], are being developed and investigated to increase combustion efficiency and reduce pollutant emissions. Therefore, the current configuration has direct or indirect relevance to the ignition of a range of practical combustor systems.

\section{EXPERIMENTAL APPARATUS AND METHODOLOGY}

In this section the apparatus employed in the study is described, along with the ignition unit, the experimental procedure and the high-speed imaging system for $\mathrm{OH}^{*}$ chemiluminescence. 


\subsection{Premixed annular combustor}

Figure 1 shows a picture of the premixed annular combustor (d), along with a schematic of the top view (a), the side view (b), and of an individual burner (c). The apparatus was adapted and developed from the one from Worth and Dawson [21, 22] and Allison et al. [23] and it was previously employed for an investigation of the $\mathrm{LBO}$ behaviour of a multi-burner configuration [24]. All details of the setup can be found in these references, thus a shorter description is provided in this paper.

Differently from Refs. [21, 22] the burner was mounted horizontally, to closely resemble realistic gas turbine combustors. The annular combustor was made of an even number of equally spaced, swirled, bluff body-stabilised burners, arranged around a circle of $170 \mathrm{~mm}$ diameter in an annular enclosure. These individual burners (see Fig. 1c) consisted of a $150 \mathrm{~mm}$ long cylindrical pipe with an inner diameter of $D_{B}=18.9 \mathrm{~mm}$. Conical bluff bodies with diameters and half angles of $D=13 \mathrm{~mm}$ and $45^{\circ}$, respectively, were fitted at the centre of each burner. Thus, the resulting blockage ratio at the exit of each burner was $50 \%$. Just upstream of each bluff body was a swirler composed of a set of six vanes (exit vane angle $\alpha=60^{\circ}$ ), which induce a counterclockwise radial flow with a geometrical swirl number of 1.22 [22]. The annular chamber was formed by a $145 \mathrm{~mm}$ long quartz glass cylinder with a diameter of $212 \mathrm{~mm}$ and by a $160 \mathrm{~mm}$ long stainless steel cylinder with a diameter of $127 \mathrm{~mm}$.

Individual burners were held in position by two metallic plates, as can be seen from the picture in Fig. 1d. Two sets of plates were employed, in order to be able to allocate 12 or 18 individual burners. As a result, the inter-burner distance was $S_{12}=2.33 D_{B}$ and $S_{18}=1.56 D_{B}$ respectively, defined as the arcdistance between the centre of two adjacent bluff-bodies. This enabled to evaluate the effect of burner-to-burner distance on the ignition probability and the ignition transient.

The experiments were carried out using methane $(99.5 \%$ pure). Three Alicat mass flow controllers, with an accuracy of $0.8 \%$ of the set value, were used to control the fuel and air flow rate. Air delivered from the compressor and methane were mixed upstream and fed into a common cylindrical plenum that was 200 $\mathrm{mm}$ long and had an inner diameter of $203 \mathrm{~mm}$. A bed of 6 $\mathrm{mm}$ diameter glass marbles was placed inside the plenum to homogenise the flow. Additionally, a honeycomb flow straightener was added just downstream of the glass marbles to ensure the flow was uniform prior to reaching the individual burners. From the common plenum, the mixture was fed into each individual burner by hitting a $140 \mathrm{~mm}$ diameter hemispherical body, positioned at the end of the cylinder and attached to the lower of the two plates, as shown in Fig. 1b. Preliminary velocity measurements with a pitot tube in a cold flow confirmed the mixture velocity was the same at the exit of each burner.

\subsection{Ignition unit, spark location and experimental conditions}

The ignition unit is composed of a pair of $0.5 \mathrm{~mm}$ stainlesssteel electrodes with a spark gap of $\sim 2 \mathrm{~mm}$, connected to a highvoltage transformer $(2 \times 5 \mathrm{kV}, 20 \mathrm{~mA})$ generating sparks lasting for approximately $10 \mathrm{~ms}$. The frequency of the spark is determined by a control system comprising a zero-crossing solid-state relay and a pulse generator, and is limited to a maximum of $100 \mathrm{~Hz}$.
TABLE 1: EXPERIMENTAL FLOW CONDITIONS.

\begin{tabular}{ccccc}
\hline \# Burners & $\begin{array}{c}\text { Spark radial loc. } \\
(r / S)\end{array}$ & $\begin{array}{c}\text { Spark long. loc. } \\
(x / D)\end{array}$ & $\phi$ & $U_{\text {mix }}$ \\
\hline 12 & 0 & $0.5,1,2,5$ & 0.58 to 0.68 & $10,20,30$ \\
12 & 0.5 & $0.5,1,2$ & 0.58 to 0.68 & $10,20,30$ \\
18 & 0 & $0.5,1,2,5$ & 0.58 to 0.68 & $10,20,30$ \\
18 & 0.5 & $0.5,1,2$ & 0.58 to 0.68 & $10,20,30$ \\
\hline
\end{tabular}

A pulse of $100 \mathrm{~ms}$ was used to trigger the ignition system. The duration of the pulse determined the number of sparks delivered, resulting in a total of 10 sparks of $10 \mathrm{~ms}$ for each test. Thus, in this study, the spark refers to a sequence of 10 individual sparks. The energy deposited with each spark was higher than the minimum ignition energy for methane for the flow conditions investigated [3].

The two rods were mounted on a variable position traverse, allowing to change the longitudinal position of the spark along the annular chamber. Figure 2 reports a schematic of the spark locations relative to the burner. The spark location was defined in cylindrical coordinates $(x, r)$ normalised by the bluff body diameter $(D)$ and the inter-burner distance $(S)$. For each condition, 7 spark locations were tested for both the 12- and 18-burner configurations, 4 along the axis of one bluff body and 3 in the middle between two adjacent burners. In a bluff body burner the flame relies on the recirculation zone (a low-velocity region formed downstream of the bluff body) for stabilisation, which usually extends for $\sim 1.5$ to 2 times the bluff body diameter [28, 29]. Thus, the positions investigated along the bluff body axis were chosen in order to be around inside $(x / D=0.5$ and $x / D=1)$, near the boundary $(x / D=2)$ or outside $(x / D=5)$ the IRZ of a single burner.

Table 1 reports the cases investigated during the experimental campaign. For each of the seven spark locations, three mixture velocities and five equivalence ratios were tested, for the 12and the 18-burner configurations. The bulk velocities reported in Table 1 were calculated from the total flow rate and the sum of the open areas from each burner. Tests were performed at a pressure of 1 bar and temperature of $293 \mathrm{~K}$.

\subsection{Ignition probability calculation}

The following procedure was followed to measure the ignition probability. First the fuel and air mass flow controllers were opened for $2 \mathrm{~s}$, to fill the annular chamber a flammable mixture before ignition, and then the spark was deposited. In case of successful ignition, the fuel supply was stopped to extinguish the flame, and the burner was let to cool down for $30 \mathrm{~s}$ prior to the next attempt. Otherwise, in case of a failed ignition, the next spark was delivered after $5 \mathrm{~s}$, to avoid any possible influence of the previous attempt. It was found that the possible outcomes of each test were: (i) the initial flame kernel grows (phase 1 and 2) and successfully starts the flame propagation (phase 3 and 4) azimuthally across the chamber igniting the entire combustor; (ii) the flame kernel quenches after the initial growth, leading to a failed ignition, mainly due to failure in phase 2 and 3 of the ignition process. Thus, it appears there is no possibility for the 


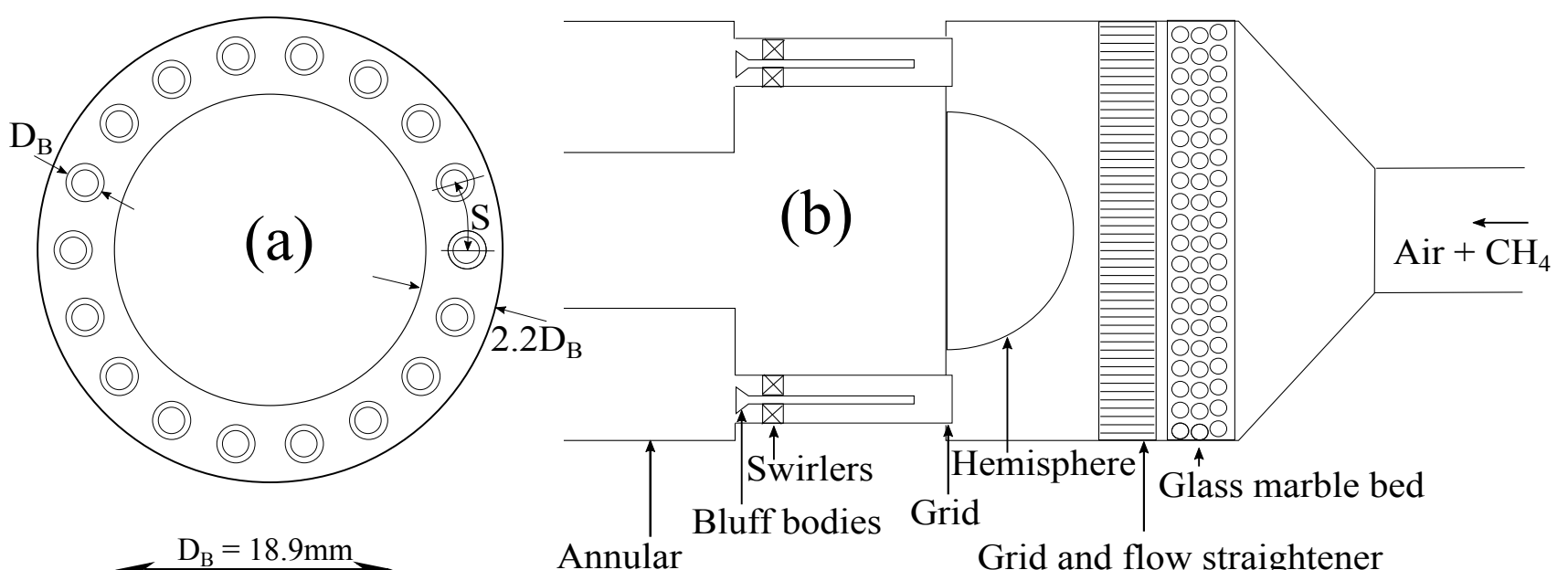

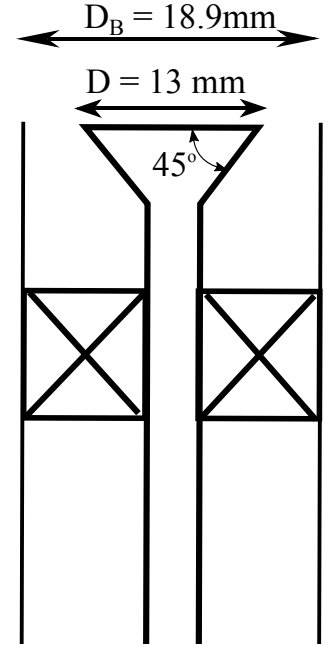

(c)

\section{Chamber}

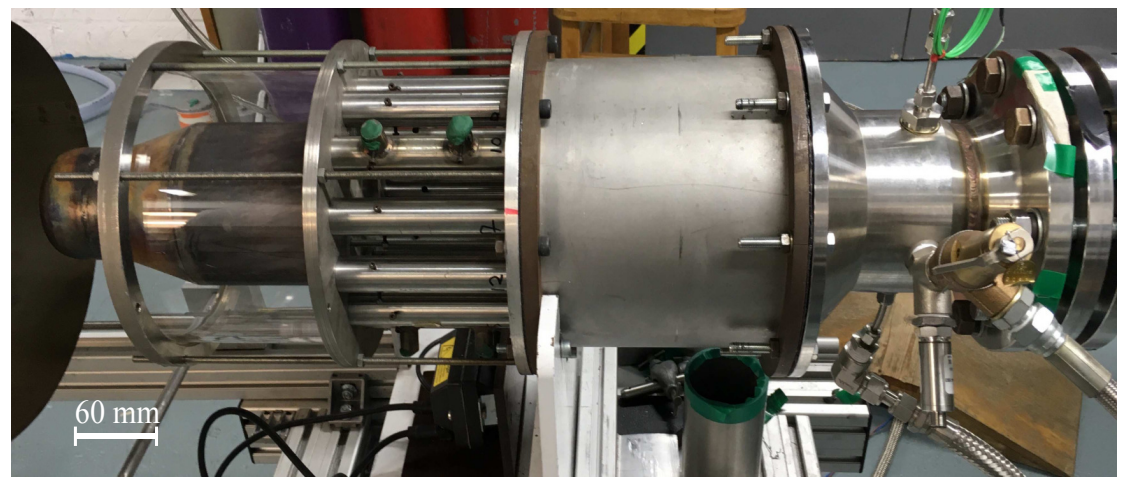

(d)

FIGURE 1: SCHEMATIC OF THE ANNULAR COMBUSTOR, PREVIOUSLY EMPLOYED IN REF [24] AS SEEN FROM THE TOP (A) AND THE SIDE (B) AND OF AN INDIVIDUAL BURNER (C). (D): PHOTOGRAPH OF THE SETUP; THE FLOW IS FROM RIGHT TO LEFT.

flame to stabilise on a single burner without leading to the complete ignition of the combustor, which means $P_{\text {ign }}=P_{\text {burner }}$. As a result, "ignition" was defined as successful stabilisation of the flame in the whole annular combustor. The ignition probability for each case was obtained from 20 tests and calculated as the number of successful events divided by the total number of attempts $(n)$. The standard error associated to this calculation can be estimated from the formula: $\left[P_{i g n}\left(1-P_{i g n}\right) / n\right]^{0.5}$, resulting in a uncertainty of $11 \%$ for $P_{i g n}=50 \%$ [13].

The focus of this paper is the investigation of the flame propagation and the flame stabilisation from the initial flame kernel. Therefore, the duration of the spark sequence was set to be long enough to ensure all the trials led to the formation of a kernel $\left(P_{\text {kernel }}=1\right)$, and unsuccessful ignition was related to failures in phases 2-4 of the ignition transient. Preliminary tests with a single spark of $10 \mathrm{~ms}$ (not reported here) showed high variability between each realisation and a strong influence of the spark stretch due to the high mixture velocity on the ignition attempts. Using a sequence of sparks allows to focus the attention on $P_{i g n}$ and not on $P_{\text {kernel }}$ and is closer to practical application, where energy is deposited multiple times [2]. It is worth mentioning that the timescale of the total ignition process, and in particular of the light-round time, was the same order of magnitude of the duration of the spark sequence. However, it was seen that, once the flame propagation started, there was no influence of the spark on the light-round, as will be explained in next section.

\section{$2.4 \mathrm{OH}^{\star}$ chemiluminescence apparatus}

The ignition transient, including ignition failures and successful flame propagation was investigated via high-speed imaging $(10 \mathrm{kHz})$ of $\mathrm{OH}^{*}$ chemiluminescence, which provides an estimate of the primary heat release rate regions [30]. The apparatus consisted of two high-speed cameras, one looking axially downstream from the exit of the combustor (referred to as "top view") and the other placed on the side of the burner, thus focused on a subset of 3 to 5 individual burners (referred to as "side view"). The two camera clocks were synchronised using an external waveform generator, in order to obtain simultaneous top and side view videos of the propagating flame front. A signal generator was used to trigger at the same time the spark generator and the video recording. Each camera was a Photron SA1.1 high-speed CMOS camera, with a maximum resolution of 768 $\times 640$ pixels at $10 \mathrm{kHz}$. Coupled to the camera was a LaVision 


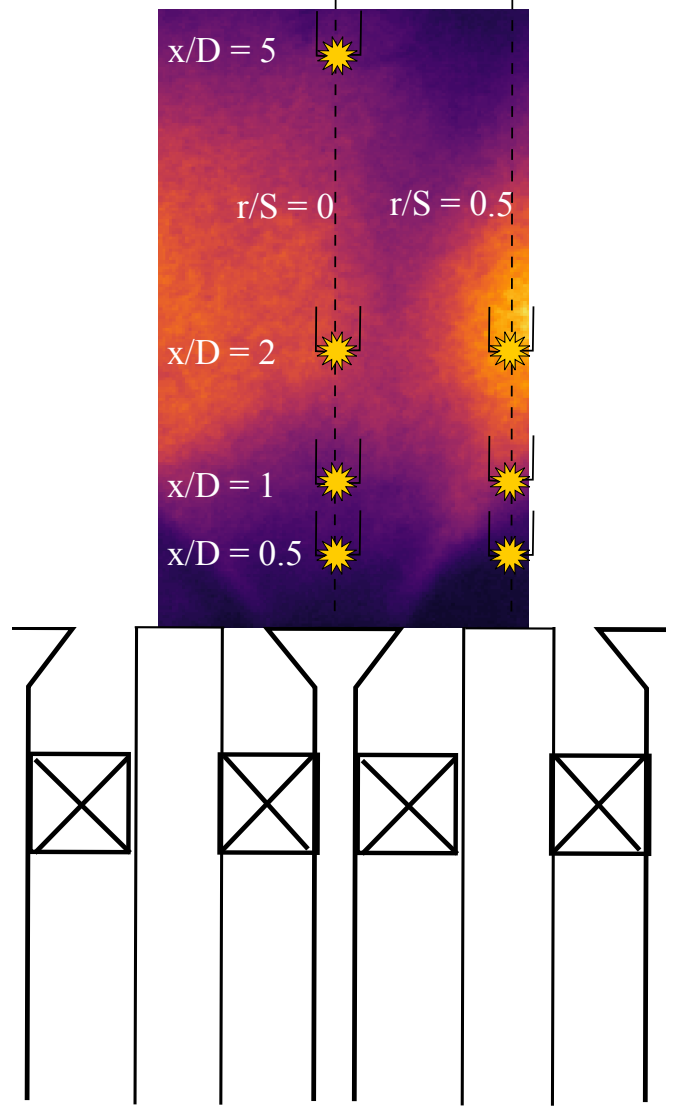

FIGURE 2: SCHEMATIC SHOWING THE SPARK LOCATIONS. AN $\mathrm{OH}^{\star}$ CHEMILUMINESCENCE IMAGE OF THE FLAME IS INCLUDED.

IRO high-speed intensifier, which was gated at $93 \mu$ s for a $10 \mathrm{kHz}$ frame rate. A UV $100 \mathrm{~mm} \mathrm{f/2.8} \mathrm{lens} \mathrm{(Cerco} \mathrm{2178)} \mathrm{fitted} \mathrm{with}$ a narrow bandpass filter $(310 \mathrm{~nm}+/-5 \mathrm{~nm})$ was attached to the IRO, used at f/2.8.

\section{RESULTS AND DISCUSSION}

This section presents the results obtained. First, the lean ignition limits are reported. Next, a visualisation of the flame is presented, showing the ignition transient and the mechanism of successful and failed ignition attempts. Finally, the ignition probability graphs are reported and discussed.

\subsection{Lean ignition limits}

In this study, the lean ignition limits were investigated for both configurations. To obtain the lean ignition curves, the spark was placed in the location were the conditions were most favourable for ignition, which means highest ignition probability, as will be discussed in the next section. Different mixture velocities were tested. A detailed description of the flame shape and characteristics at stable conditions can be found in Ref. [24]. The stable flame appeared attached to the bluff bodies and the individual flames seemed to merge in the inter-burner region, suggesting high level of interaction, especially for the 18-burner case.

Figures $3 \mathrm{a}$ and $3 \mathrm{~b}$ report the graphs with the lean ignition limits for the 12- and 18-burner configurations, compared to the LBO stability limits (retrieved from Ref. [24]). The stability curves are presented in terms of equivalence ratio vs mixture velocity, as commonly reported for flames stabilised in the presence of a flameholder [1]. Namely, three kind of flames can be ignited in the system (see pictures in Figs $3 a$ and $3 b$ ), depending on the mixture characteristics ( $\phi$ and $U_{\text {mix }}$ ): (i) stable flame, attached to all the individual bluff-bodies, (ii) bouncing flame, characterised by a pattern of lift-off and detachment of the flame from individual burners across the chamber, (iii) fully lifted flame, completely lifted from all the bluff bodies. Although fully lifted flames can survive in this annular combustor, such a burning mode is not desirable for practical applications, thus the lifted flame limit can be considered as the lean stability limit for the burner. Similar flame structures were observed in the LBO study in Ref. [24].

In both configurations, at each mixture velocity the lean ignition limit is at an higher $\phi$ than the corresponding LBO limit. Such difference seems to be higher in the 18-burner compared to the 12-burner configuration. This finding is in agreement with the typical stability curves obtained for gas turbine combustors [1] and was reported also for premixed and non-premixed bluff body stabilised flames and counter-flow flames [14, 15, 18, 19]. It is worth noticing that the ignition tests are performed at ambient temperature, while when performing a lean blow-off test the burner is kept running for $\sim 3-4$ min to gradually reach lift-off, thus heating the burner. The temperature difference could have an impact on the stability of the system.

To facilitate a comparison of the lean ignition curves for the 12- and 18- burner configuration, they are plotted on the same graph in Fig. 4. It was noticed that the 12-burner system appears to be more 'stable' (i.e. can be ignited and stabilised at lower $\phi)$ than the 18-burner. Same trend was reported for the LBO curves in Ref. [24]. This means that, for the same mixture velocity, the transition to bouncing flame and then to completely lifted happened at a lower equivalence ratio when the inter-burner distance was increased (reducing the number of burners). It could be due to the higher level of interaction between adjacent flames in the 18-burner, which leads to higher strain in the inter-burner region and impedes flame propagation and stabilisation close to the bluff body. Moreover, for the same mixture velocity, the total flow rate is larger in the 18-burner setup (more open area), resulting in an increase in the velocity in the annular chamber downstream of the bluff bodies. This could affect the process of stabilisation and the upstream propagation of the flame front.

\subsection{Visualisation of the ignition transient}

Figure 5 shows four ignition sequences for the 12-burner configuration for two different spark locations, from the side view. Namely, in Figs. 5a and b the spark is located at a longitudinal location of $x / D=2$ and a radial location of $r / S=0.5$, and in Figs. $5 \mathrm{c}$ and $\mathrm{d}$ the spark was at the same longitudinal location, while radially positioned on top of a bluff body $(r / S=0)$. All the four sequences are at the same flow conditions $\left(U_{\text {mix }}=30 \mathrm{~m} / \mathrm{s}\right.$ and $\phi=0.65)$.

The sequences in column (a) and (c) report a failed attempt to obtain ignition, while in (b) and (d) the initial phases of a successful ignition are shown. The initial time $t_{0}$ was chosen to be initial instant of a spark. As discussed in section 2.2 each test comprised continuously sparking for 100 ms, with 10 sparks 


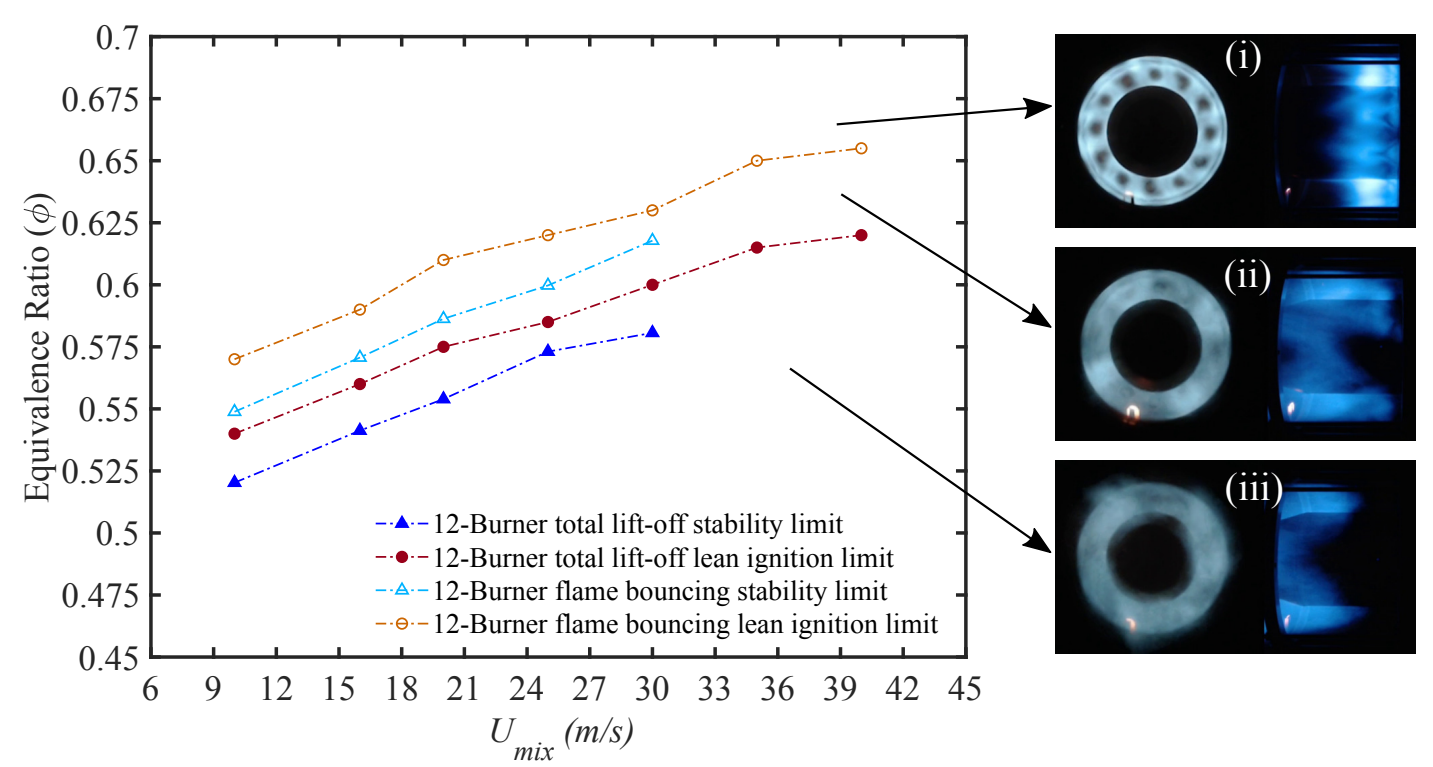

(a)

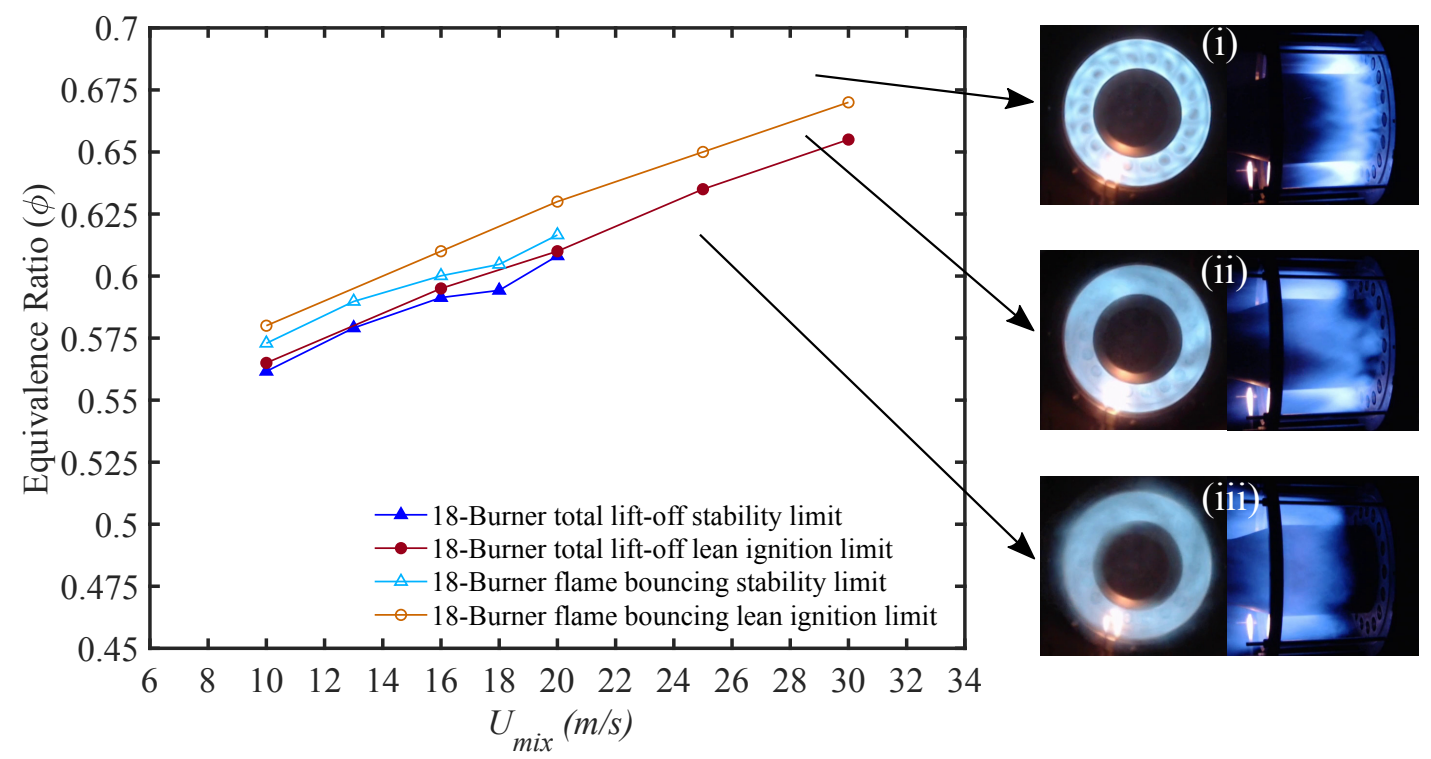

(b)

FIGURE 3: COMPARISON OF THE STABILITY LIMITS (FROM THE BLOW-OFF STUDY IN REF. [24]) AND THE LEAN IGNITION LIMITS FROM THE PRESENT EXPERIMENTS FOR THE 12-BURNER (A) AND THE 18-BURNER (B) CONFIGURATIONS. THE FLAME SHAPES CORRESPONDING TO THE THREE REGIMES ARE SHOWN IN THE PHOTOGRAPHS. (I) STABLE FLAME; (II) BOUNCING FLAME; AND (III) FULLY LIFTED FLAME.

of $10 \mathrm{~ms}$ each, so $t_{0}$ could be at the beginning of any of the 10 sparks.

In Fig. 5a the formation of a flame kernel $(t=5.4 \mathrm{~ms})$ was noticed, which subsequently grows and is convected towards the bluff body ( $t=7.9 \mathrm{~ms}$ ). The spark is located between two burners $(r / S=0.5)$ and the propagation of the kernel follows the swirl direction (confirmed by the top view images, not shown here). Once the flame appears to be inside the $\operatorname{IRZ}(t=9.9 \mathrm{~ms})$ it undergoes localised quenching on the bluff body and extinguishes $(t=11.1 \mathrm{~ms})$. The localised quenching is probably due to the heat losses to the bluff body. This is the reason for the failure of the ignition attempt. In addition, the IRZ appears to be 'trapping' the incipient flame, preventing the propagation in the azimuthal direction and favouring flame extinction. Failure can be therefore be placed between phase 2 and 3 of the ignition process.

Fig. 5b shows a time series of successful ignition event, from the same conditions. At $t=t_{0}$ it is still possible to distinguish some $\mathrm{OH}^{*}$ chemiluminescence signal, coming from the kernel generated from the previous spark. Sustained by the energy deposited by the spark, the flame kernel grows $(t=6.3 \mathrm{~ms})$ and is capable of propagating to the closest burner following the direction of the swirl. In this case, the propagation is both upstream towards the bluff body and inside the chamber $(t=11.3$ $\mathrm{ms})$. Once the flame kernel grows enough in the chamber, it start propagating azimuthally ( $t=13.3 \mathrm{~ms}$ to $17.8 \mathrm{~ms}$ ), leading to the beginning of the light-round $(t=23.3 \mathrm{~ms})$ and eventually the 


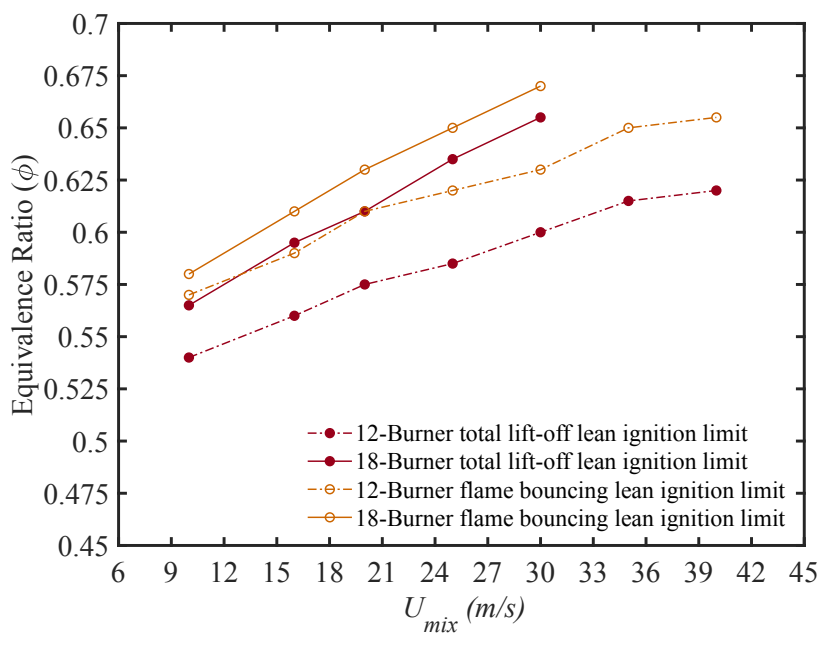

FIGURE 4: COMPARISON OF THE LEAN IGNITION LIMITS BETWEEN THE 12- AND 18- BURNER CONFIGURATIONS.

ignition and stabilisation of the flame in the entire combustor. The success in the ignition process is due to the possibility for the flame kernel to survive and grow away from the bluff-body in order to spread to the next burner. Even in case of a premixed mixture, the presence of different patterns of evolution of the flame kernel confirms the strong influence of stochasticity in the ignition process. The level of turbulence, the local high strain and the low mixture strength (lean equivalence ratio) cause the flame to randomly propagate or quench depending on the local flow conditions.

The same behaviour was observed when the spark was located at a radial location $r / S=0$ (see Figs. $5 \mathrm{c}$ and $5 \mathrm{~d}$ ), probably close to the edge of the IRZ of one burner. In Fig. $5 \mathrm{c}$ a flame kernel can be observed developing around the spark $(t=3.6 \mathrm{~ms})$, in the form of high intensity $\mathrm{OH}^{*}$ signal. Following this, the kernel grows $(t=7.6 \mathrm{~ms})$, propagating upstream, captured by the flow in the IRZ. As a result, the flame kernel, only sustained by the energy deposited by the spark, is quenched on the bluff body $(t=11.6 \mathrm{~ms})$ and eventually disappears $(t=19.6 \mathrm{~ms})$. The reason for the failure is again the failure in flame spreading from one burner, followed by local extinction on the bluff body due to heat losses. The only difference is that the incipient flame was confined to the IRZ for the entire process. The ignition event in Fig. 5d shows how the flame can successfully develop in the same condition. The main difference is that the initial kernel starts propagating azimuthally $(t=6.5 \mathrm{~ms})$ and upstream, growing in the annular chamber $(t=14.5 \mathrm{~ms}$ to $23.5 \mathrm{~ms})$ until the beginning of the light-round ( $t=30.5 \mathrm{~ms}$ ). In summary, most failure events observed follow the path described here: (i) formation of a flame kernel around the spark, (ii) convection and propagation of the flame kernel upstream towards the bluff body, (iii) trapping of the incipient flame inside the IRZ, (iv) localised quenching on the bluff body due to heat losses.

Flame spreading is therefore the crucial point of the ignition process and was seen to be different depending on the spark location and inter-burner distance. Examples of different patterns of initial flame propagation leading to successful ignition

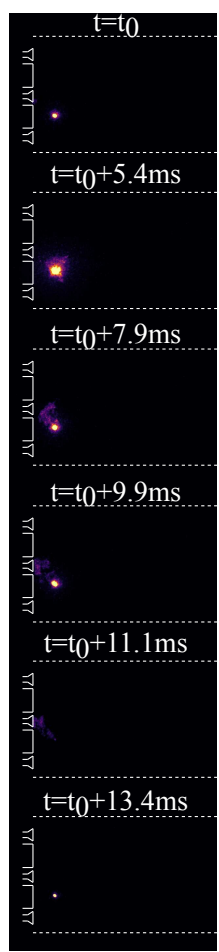

(a)

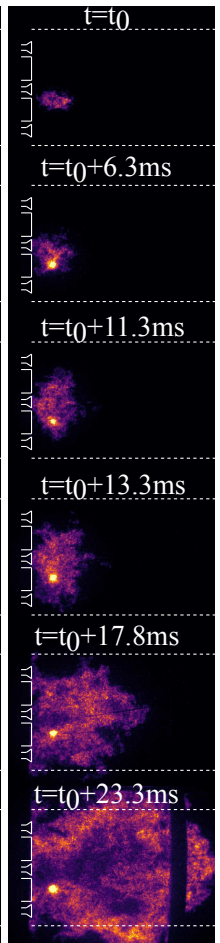

(b)

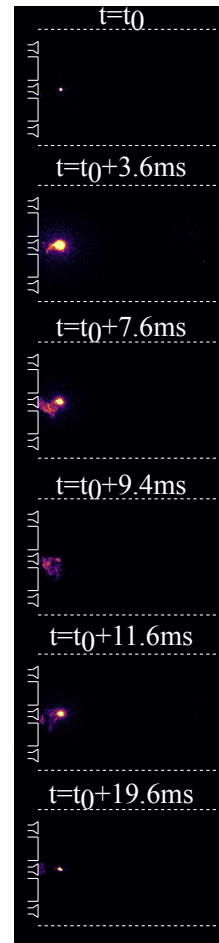

(c)

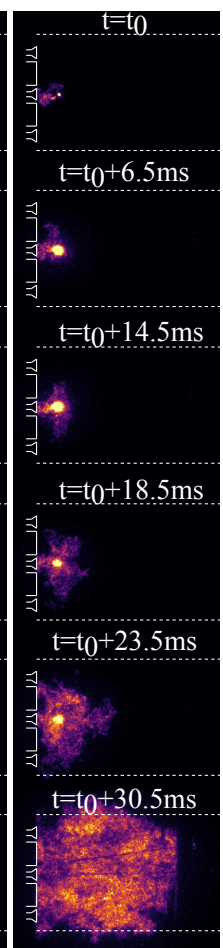

(d)
FIGURE 5: OH$^{\star}$ SEQUENCES OF FAILED, (A) AND (C), AND SUCCESSFUL, (B) AND (D), IGNITION EVENTS IN THE 12-BURNER CONFIGURATION $\left(U_{\text {mix }}=30 \mathrm{~m} / \mathrm{s}, \phi=0.65\right)$, SIDE VIEW. IN (A) AND (B) THE SPARK LOCATION IS $x / D=2$ AND $r / S=0.5$, WHILE IN (C) AND (D) THE SPARK IS LOCATED AT $x / D=2$ AND $r / S=0$.

are reported in Fig. 6. In particular, when sparking at $x / D=0.5$ ignition was more difficult (as will be shown in the ignition probability graphs in next section), resulting in a more complex and stochastic flame propagation.

The first pattern is shown in Fig 6a where an image sequence of a test in the 12-burner configuration with the spark located close to the bluff body is reported. It is possible to see the formation of the initial kernel very close to the spark rods $(t=3.8$ ms and $t=7.3 \mathrm{~ms}$ ), which is able to survive and be convected by the flow. The turning point is represented by the spreading of the flame edge (represented by the triangles at $t=14 \mathrm{~ms}$ and $t=21.3 \mathrm{~ms}$ ) that overcomes the single burner and start travelling azimuthally across the chamber. Following, the flame starts developing $(t=21.3 \mathrm{~ms}$ and $t=31.8 \mathrm{~ms})$, initiating the light-round from the bottom part of the chamber. A similar behaviour was observed in the case of the 18-burner configuration for a spark located at $x / D=2$, shown in the image sequence in Fig 6d. However, the flame growth is mostly proceeding downstream and azimuthally ( $t=4.9 \mathrm{~ms}$ to $12.4 \mathrm{~ms}$, see also the white triangle), while only propagating upstream during the ignition of the entire chamber $(t=24.9 \mathrm{~ms})$. This suggests that the flow conditions close to the bluff body are not favourable for the flame kernel to survive and grow. It could be due to the high strain in the inter-burner region due to the interaction between adjacent flow streams and the turbulence level, more evident in the 18-burner configuration where burners are closer to each other. 


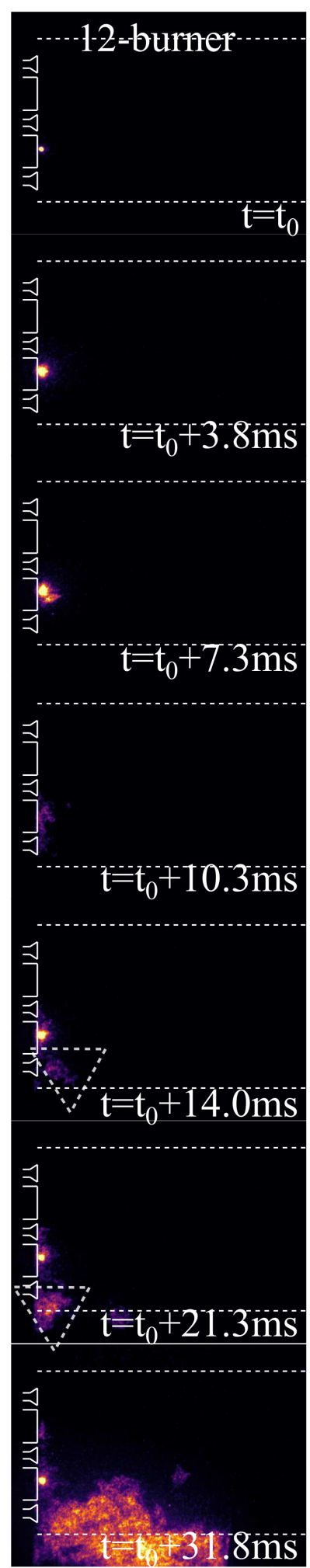

$(\mathrm{x} / \mathrm{D}=0.5, \mathrm{r} / \mathrm{S}=0.5)$

(a)
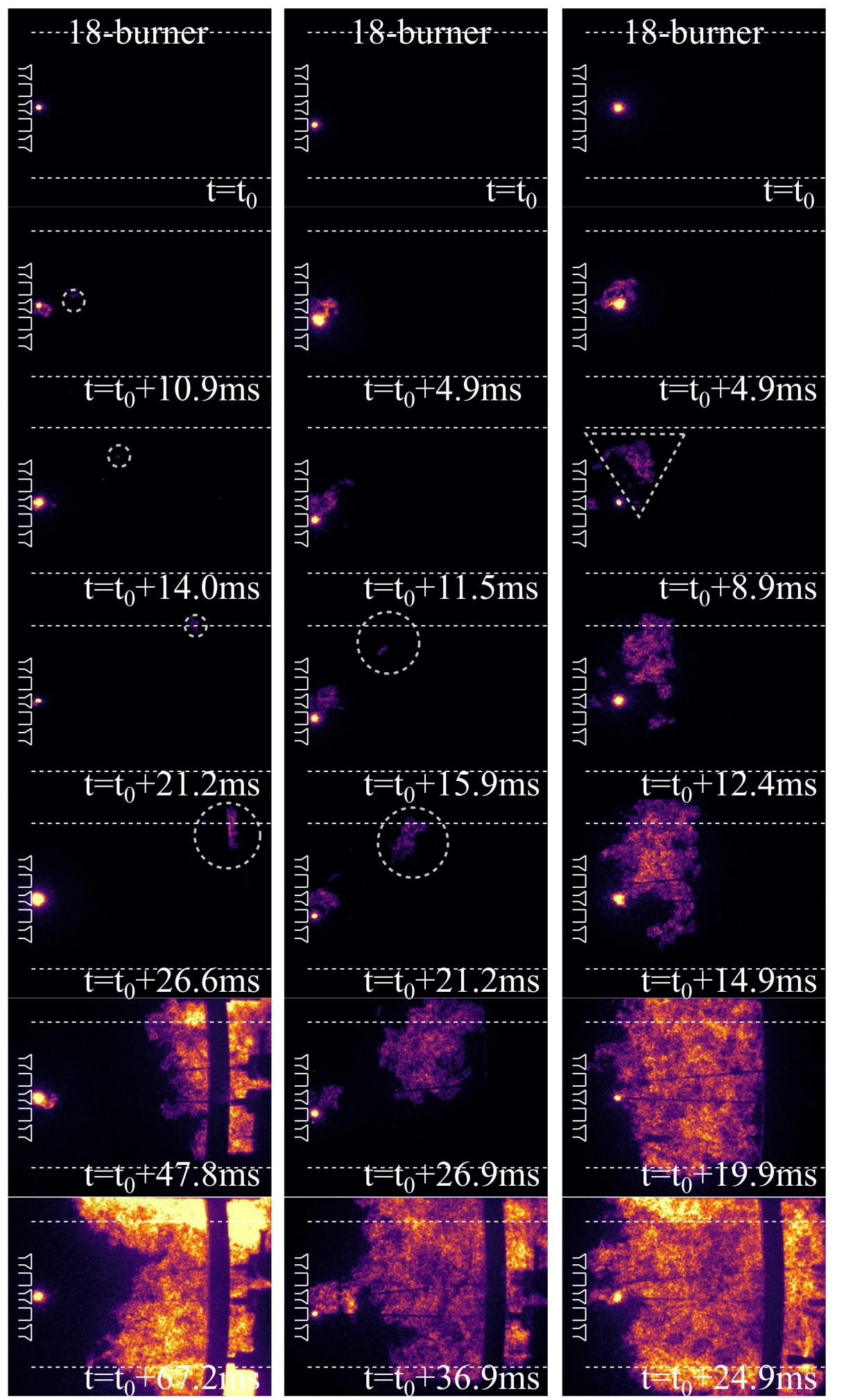

$(\mathrm{x} / \mathrm{D}=0, \mathrm{r} / \mathrm{S}=0.5)$

(b)

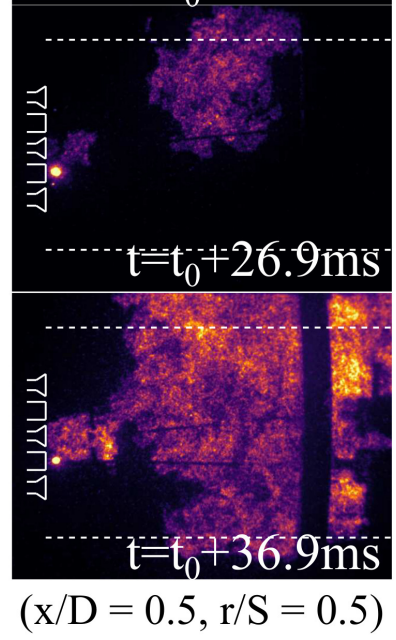

(c)

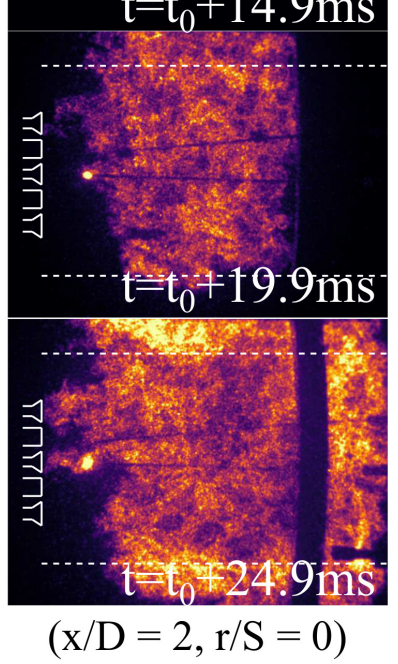

(d)

FIGURE 6: OH` SEQUENCES OF SUCCESSFUL IGNITION EVENTS FOR FOUR DIFFERENT SPARK LOCATIONS, IN THE 12-BURNER (A) AND 18BURNER (B,C AND D) CONFIGURATIONS. THE SPARK LOCATION IS INDICATED AT THE BOTTOM OF EACH COLUMN. THE FLOW CONDITIONS ARE $U_{m i x}=20 \mathrm{~m} / \mathrm{s}$ AND $\phi=0.65 \mathrm{FOR}(\mathrm{A})$, (C) AND (D), AND $U_{m i x}=30 \mathrm{~m} / \mathrm{s}$ AND $\phi=0.68 \mathrm{FOR}$ FIGURE (B). 


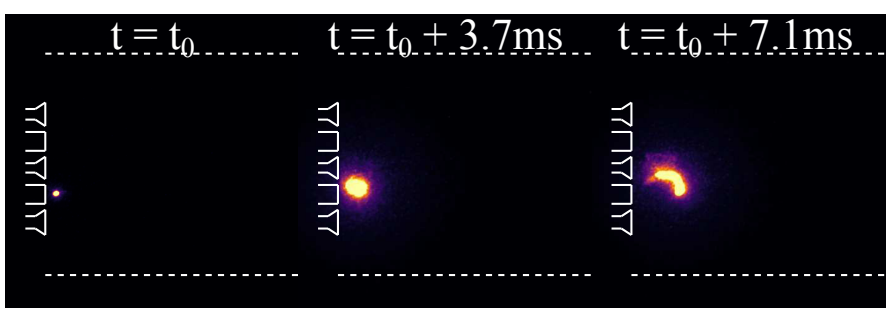

FIGURE 7: $\mathrm{OH}^{\star}$ CHEMILUMINESCENCE SEQUENCE SHOWING THE SPARK DISTORTION IN THE 18-BURNER SYSTEM. SPARK LOCATED AT $x / D=0.5$ AND $r / S=0.5$. MIXTURE CHARACTERISTICS: $U_{m i x}=20 \mathrm{~m} / \mathrm{s}$ AND $\phi=0.65$.

In addition, velocity (thus turbulence intensity) is maximum at the exit of the burner, while it is decreasing downstream.

A second flame propagation pattern, that appears to support this explanation for the 18-burner configuration, is presented in Figs. $6 \mathrm{~b}$ and $6 \mathrm{c}$. In both image sequences the spark is located at $x / D=0.5$ while the radial location is $r / s=0$ and $r / s=0.5$ respectively. When the spark is very close to the bluff body, the initial kernel cannot grow and propagate, as if the flow conditions are too harsh for ignition. In particular, at $r / s=0$ the initial flame kernel is inside the IRZ and suffers from heat losses on the bluff-body, while at $r / s=0.5$ it is probably the high level of strain that can lead to localised quenching. As a result, the flame propagation appears to be related to the possibility for a flame kernel to survive and be convected away from the IRZ and the bluff-body downstream in the combustion chamber. In Fig. $6 \mathrm{~b}$ after $10 \mathrm{~ms}$ from the spark it is possible to see a separate flame kernel travelling inside the chamber (indicated by a white circle) in the form of a pocket of signal of $\mathrm{OH}^{*}$ chemiluminescence. This pocket is further convected downstream $(t=14 \mathrm{~ms}$ to $t=21.2$ $\mathrm{ms}$ ), until the local flow conditions become favourable for the beginning of the flame propagation. As the velocity drops from the small annulus of each burner to the annular chamber, due to a bigger flow-through area, the flame kernel can start to grow and the flame subsequently propagates upstream $(t=26.6 \mathrm{~ms})$, igniting the fresh reactants and eventually leading to the ignition of the entire burner. Similar behaviour is shown in $6 \mathrm{c}$, when the spark is located in the middle between two adjacent burners. After $\sim 12$ ms a pocket of $\mathrm{OH}^{*}$ is convected along the chamber and starts growing (see the white circles in the image sequence). When a critical size is reached, the propagation begins in the upstream direction $(t=26.9)$ and simultaneously in the azimuthal direction, eventually igniting the combustor. The only difference compared to the previous case is that flame growth appears to be gradual while the kernel is convected, instead of being concentrated in the far downstream region of the combustion chamber.

The high turbulence intensity and the long duration of each spark can also lead to the distortion of the spark [20], resulting in an increase in the stochasticity of the ignition process. Such behaviour was mainly found in the 18-burner configuration, where the total flow rate (for the same bulk velocity) was larger than the 12-burner case. An example of this phenomenon is reported in Fig. 7. The image sequence shows how the spark can be stretched by the flow, starting from a size $\sim-3 \mathrm{~mm}$ and evolving towards $\sim$ 1-2 D. Similar behaviour was observed in Ref. [20] in a high turbulent spray, bluff body flame. The interaction between the flow and the spark can impact the ignition process and favour the formation of flame pockets in regions of favourable conditions for the flame propagation.

\subsection{Ignition probability}

The ignition probability was obtained following the procedure described in section 2.3, and the conditions tested are reported in Table 1. Figs. 8a and $8 \mathrm{~b}$ report the graphs showing $P_{i g n}$ in the 12- and 18- burner configuration.

In the figures each square represents one spark location, defined in terms of radial $(r / S)$ and longitudinal $(x / D)$ location and the colour of the filling is scaled according to the ignition probability. It is possible to observe similar trends for both configurations. $P_{i g n}$ grows when going from the bottom left to the top right of each figure. It means that increasing equivalence ratio and reducing mixture velocity results in an increase in the probability of ignition. Similar findings were reported in single burner systems experiments [14, 15, 17, 18], and could be attributed due to the increase in flame speed and decrease of local turbulence intensity, both favouring the growth of the initial flame kernel.

As previously described, the bottleneck of the ignition process is the propagation of the initial flame kernel to the adjacent burner. The presence of a recirculation zone due to the combined effect of swirl and bluff body is fundamental for the stabilisation of the flame, creating a low-velocity region the flame can anchor to. However, it appears that sparking inside the recirculation zone behind each burner in this annular combustor is strongly detrimental for the success of the ignition event. In the 12-burner configuration (see Fig. 8a) $P_{i g n}$ is zero or close to zero when the spark is located at $x / D=0.5$ and $x / D=1$ for all the mixtures examined at a bulk velocity of $20 \mathrm{~m} / \mathrm{s}$ and $30 \mathrm{~m} / \mathrm{s}$ and rises only at $\mathrm{U}_{\text {mix }}=10 \mathrm{~m} / \mathrm{s}$ when increasing the equivalence ratio. In addition, it appears that the ignition probability is slightly higher when the spark is located between two burners $(r / S=0.5)$ than on top of a single burner $(r / S=0)$. Also, sparking at a longitudinal location of $x / D=2$ increases the chances of successful ignition, especially at $r / S=0.5$. These findings can be explained considering the initial propagation mechanism shown in the previous section and the location of the spark relative to the bluff-body.

When the spark is located inside the recirculation zone $(x / D=0.5$ and 1$)$, the initial kernel is trapped close to the bluff body in a low velocity region. Thus, the flame cannot propagate outside the single burner and is quenched by heat losses on the bluff body. It is probable that the high strain level between the adjacent burners due to the interaction of the flow-fields prevents the spreading of the flame edge, confining the kernel to its initial location. Such finding is opposite to what was reported for premixed flames in single burner configurations in Refs. [14, 15]. In both studies, it is reported the region of highest ignition probability is the recirculation zone behind the bluff body. It is noteworthy to mention that these two burners were bluff body stabilised, without swirl, and in Ref. [15] the flame is unconfined. It is clear that the presence of burner-to-burner interactions and the global flow patterns in the annular chamber strongly affect the flame propagation. Therefore it seems unlikely to predict the behaviour of the combustor from simpler configurations. 

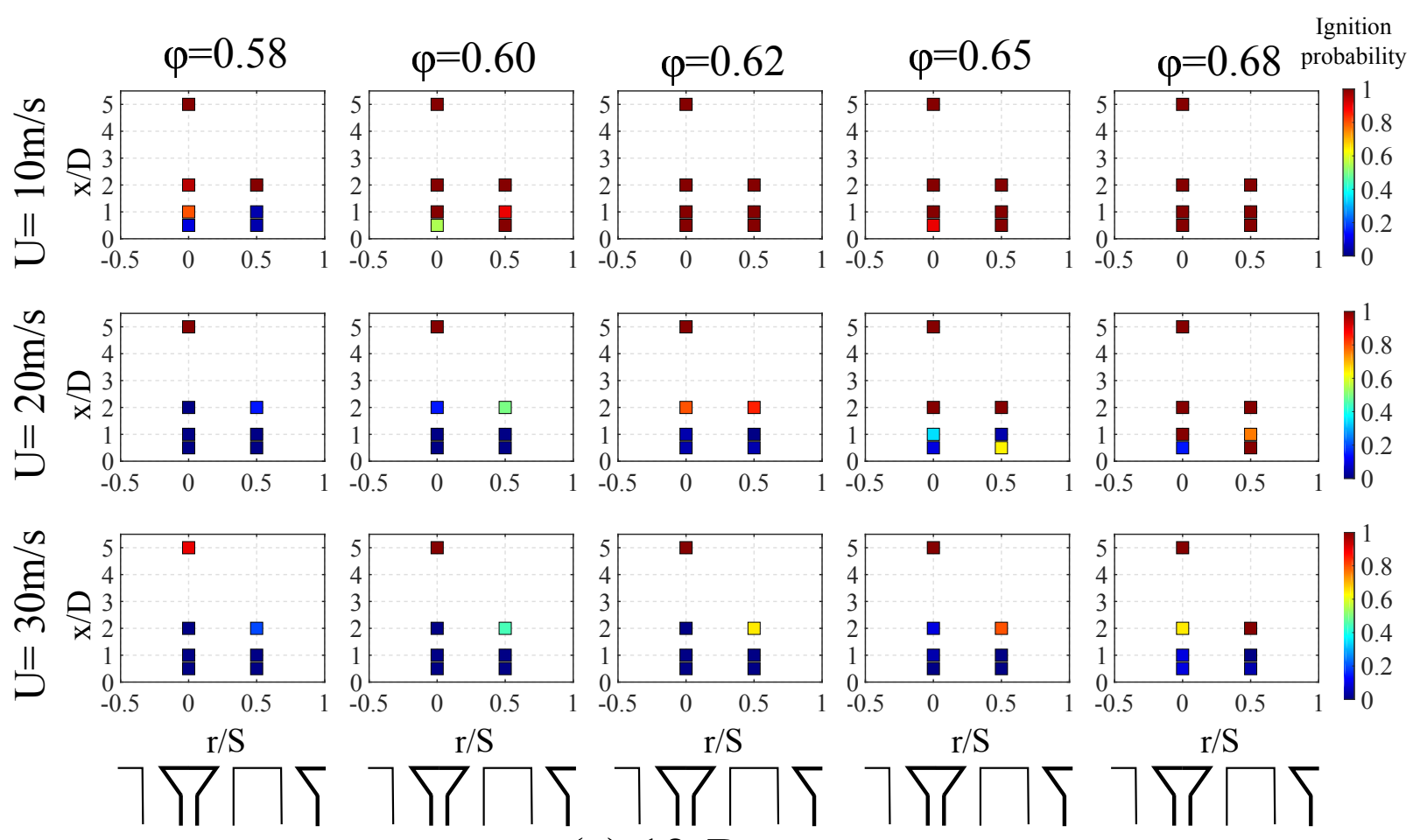

(a) 12-Burner
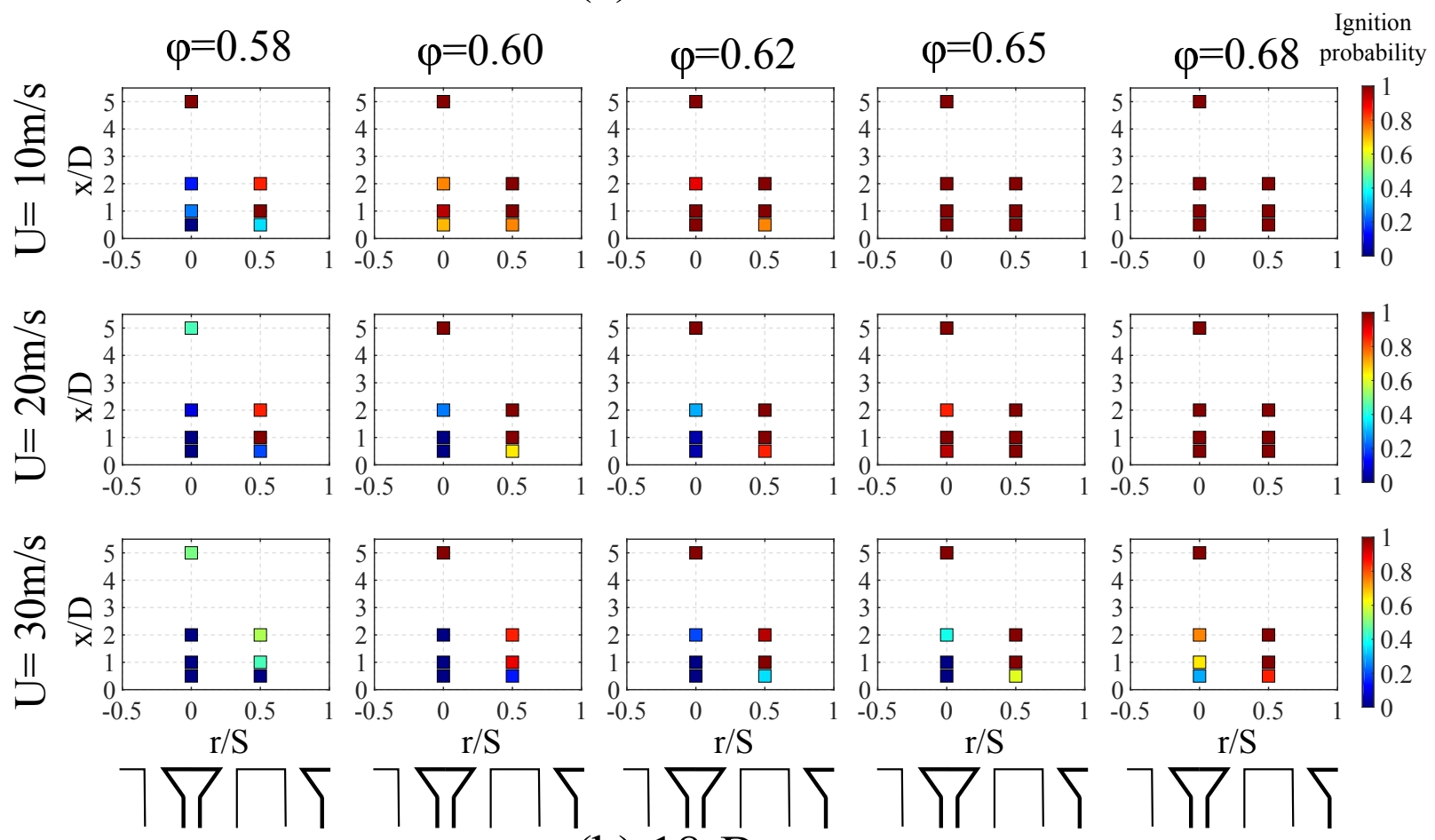

(b) 18-Burner

FIGURE 8: GRAPHS OF IGNITION PROBABILITY FOR THE 12-BURNER (A) AND 18-BURNER (B) CONFIGURATIONS. EACH SQUARE INDICATES A SPARK LOCATION AND THE COLOUR GIVES THE IGNITION PROBABILITY. A SKETCH OF THE BURNERS IS INCLUDED AT THE BOTTOM TO CLARIFY THE SPARK LOCATIONS RELATIVE TO THE INDIVIDUAL BURNERS.

Placing the spark between two burners increases the chances for the initial kernel to spread across more than one burner, thus explaining the increase in $P_{i g n}$ of up to $100 \%$ (depending on the flow conditions). On the other hand, when the spark was located at the downstream edge of the recirculation zone $(x / D=2)$, the increase in ignition probability may be due to the possible convection of the flame kernel downstream (due to the mean flow) and azimuthally (following the swirl direction) and subsequently 
propagate where the flow conditions are more favourable. As mentioned in the previous section, bulk velocity downstream in the annular chamber is far lower than close to the burner exit which results in a lower turbulence intensity. The flow conditions are therefore more favourable for kernel growth and the initial flame propagation $[14,15,20]$. This explains one result that is clearly evident from the graphs: when the spark is located at $x / D=5$ for almost all the conditions $P_{i g n} \sim 1$. The local flow conditions allow the flame growth and propagation upstream against the mean flow, driven by the turbulent flame speed of the mixture. As all the mixture are flammable, if the kernel is not quenched, upstream propagation can always occur, eventually leading to the complete ignition of the burner. This spark location was chosen for the evaluation of the lean ignition limits reported in Fig. 4.

The ignition probability charts for the 18-burner system, reported in Fig. 8b), are similar to the 12-burner, and the same considerations are valid. Although the stability limits of the 18burner are narrower (see Fig. 4) it is possible to notice that the $P_{i g n}$ is the same or even higher than the 12-burner case in some locations. In particular, it appears that in the 12-burner intermediate values of $P_{i g n}$ can be found for condition in the middle range of $\phi$ and $U_{\text {mix }}$ while $P_{i g n}$ sharply changes from $0.8-1$ to $\sim 0$ when moving from the top right to the bottom left of the chart. In addition, when the spark is located close to the bluff body, it seems that it is easier to achieve ignition in the 18-burner compared to the 12-burner case. The possible explanation is that as the inter-burner distance is reduced the chance for a flame fragment to be convected away from a bluff-body towards the adjacent burner increases. Moreover, the high turbulent intensity in the inter-burner region, though detrimental for the initial formation and growth of the kernel, could potentially help the flame propagation for a successful ignition.

\section{CONCLUSIONS}

The lean ignition behaviour and the ignition probability in a premixed annular combustor were assessed. Two configurations, with 12 and 18 burners, were tested over a range of bulk velocities (10 to $30 \mathrm{~m} / \mathrm{s}$ ) and equivalence ratios $(0.58$ to 0.68$)$. The lean ignition limits of the combustor were measured and compared to the lean blow-off (LBO) limits. It was found that the structure of the flame was qualitatively the same whether igniting at stable condition and gradually reducing $\phi$ or igniting a lean mixture, but the lean ignition limits were at higher $\phi$ compared to the LBO limits. Moreover, the 12-burner configuration is more stable than the 18-burner system, both in terms of lean ignition limits and LBO limits.

High-speed imaging $(10 \mathrm{kHz})$ of $\mathrm{OH}^{*}$ chemiluminescence was employed to shed light on the mechanism of successful ignition and failure. Successful ignition of the combustor was found to be dependent on the possibility for a flame kernel to be convected or propagate away from the bluff-body, to reach the adjacent burner. The most observed failure mechanism followed these steps: (i) formation of the flame kernel around the spark, (ii) growth of the kernel and simultaneous convection towards the bluff body due to the flow conditions, (iii) trapping of the flame kernel inside the IRZ and localised quenching on the bluff body due to heat losses. Different patterns of propagation where found for promoting a successful initiation of an ignition event, such as: (i) azimuthal propagation of the expanding flame kernel simultaneous to the upstream convection towards the bluff body (ii) convection of a $\mathrm{OH}$ pocket downstream in the burner where is able to grow due to favourable flow conditions (low velocity and turbulence intensity) and eventually propagate.

The ignition probability was measured by performing 20 separate tests for each condition, with "ignition" defined as successful ignition of the whole annular combustor, i.e. all individual burners ignited. The results showed an increase in $P_{i g n}$ when decreasing bulk velocity or increasing $\phi$, and a strong dependence on the spark location. In particular, sparking close to the bluff body resulted in $P_{i g n} \sim 0$ for most conditions examined, while $P_{i g n}$ increased with a spark located at the edge of the IRZ or between two burners. The reason was the enhanced possibility for a flame fragment to successfully initiate propagation, spreading from the first burner to the adjacent one. This finding is in contrast with what was previously found in single burner configurations, where the most favourable spark locations were seen to be inside the IRZ.

Overall, the results provided an investigation of the most favourable conditions to successfully achieve ignition in a premixed annular combustor, a major concern when designing leanoperating, low-emissions gas turbine combustors. In addition, the study highlights the importance of performing studies on multiburner geometries, as the ignition probability maps dramatically change when including burner-to-burner interaction and flame propagation compared to a single burner system.

\section{ACKNOWLEDGMENTS}

This work has received funding from the European Union's Horizon 2020 Research and Innovation Programme under the Marie Skłodowska-Curie Grant Agreement No.765998 as part of project "Annulight."

\section{REFERENCES}

[1] Lefebvre, Arthur W. and Ballal, Dilip R. Gas Turbine Combustion-Alternative fuels and emissions. CRC press, Taylor and Francis group, NY (2010).

[2] Lieuwen, Tim C. and Yang, Vigor. Gas Turbine Emissions. Cambridge University Press (2017).

[3] Glassman, Irvin and Yetter, Richard A. Combustion. Academic Press (2008).

[4] Mastorakos, Epaminondas. "Ignition of turbulent nonpremixed flames." Progress in Energy and Combustion Science Vol. 35, No. 1 (2009): pp. 57-97. DOI 10.1016/j.pecs.2008.07.002.

[5] Mastorakos, Epaminondas. "Forced ignition of turbulent spray flames." Proceedings of the Combustion Institute Vol. 36, No. 2 (2017): pp. 2367-2383. DOI 10.1016/j.proci.2016.08.044.

[6] Bourgouin, Jean-François, Durox, Daniel, Schuller, Thierry, Beaunier, Jérôme and Candel, Sébastien. "Ignition dynamics of an annular combustor equipped with multiple swirling injectors." Combustion and Flame Vol. 160, No. 8 (2013): pp. 1398-1413. DOI 10.1016/j.combustflame.2013.02.014. 
[7] Machover, Edouard and Mastorakos, Epaminondas. "Experimental investigation on spark ignition of annular premixed combustors." Combustion and Flame Vol. 178 (2017): pp. 148-157. DOI 10.1016/j.combustflame.2017.01.013.

[8] Xia, Yifan, Linghu, Changhong, Zheng, Yao, Ye, Chenran, $\mathrm{Ma}$, Chengbiao, Ge, Haiwen and Wang, Gaofeng. "Experimental Investigation of the Flame Front Propagation Characteristic During Light-round Ignition in an Annular Combustor." Flow, Turbulence and Combustion Vol. 103, No. 1 (2019): pp. 247-269. DOI 10.1007/s10494-019-00018-y.

[9] Machover, Edouard and Mastorakos, Epaminondas. "Spark ignition of annular non-premixed combustors." Experimental Thermal and Fluid Science Vol. 73 (2016): pp. 64-70. DOI 10.1016/j.expthermflusci.2015.09.008.

[10] Prieur, Kevin, Durox, Daniel, Beaunier, Jérôme, Schuller, Thierry and Candel, Sébastien. "Ignition dynamics in an annular combustor for liquid spray and premixed gaseous injection." Proceedings of the Combustion Institute Vol. 36, No. 3 (2017): pp. 3717-3724. DOI 10.1016/j.proci.2016.08.008.

[11] Prieur, Kevin, Durox, Daniel, Vignat, Guillaume, Schuller, Thierry and Candel, Sébastien. "Flame and Spray Dynamics During the Light-Round Process in an Annular System Equipped With Multiple Swirl Spray Injectors." Volume 4B: Combustion, Fuels, and Emissions: p. V04BT04A037. 2018. American Society of Mechanical Engineers. DOI 10.1115/GT2018-76840.

[12] Birch, A, Brown, D.R. and Dodson, M.G. "Ignition probabilities in turbulent mixing flows." Symposium (International) on Combustion Vol. 18, No. 1 (1981): pp. 17751780. DOI 10.1016/S0082-0784(81)80182-8.

[13] Smith, M.T.E., Birch, A.D., Brown, D.R. and Fairweather, M. "Studies of ignition and flame propagation in turbulent jets of natural gas, propane and a gas with a high hydrogen content." Symposium (International) on Combustion Vol. 21, No. 1 (1988): pp. 1403-1408. DOI 10.1016/S00820784(88)80372-2.

[14] Ahmed, Samer F. "The probabilistic nature of ignition of turbulent highly-strained lean premixed methane-air flames for low-emission engines." Fuel Vol. 134 (2014): pp. 97106. DOI 10.1016/j.fuel.2014.05.052.

[15] Sitte, Michael Philip, Bach, Ellen, Kariuki, James, Bauer, Hans-Jörg and Mastorakos, Epaminondas. "Simulations and experiments on the ignition probability in turbulent premixed bluff-body flames." Combustion Theory and Modelling Vol. 20, No. 3 (2016): pp. 548-565. DOI 10.1080/13647830.2016.1155756.

[16] Cordier, M., Vandel, A., Cabot, G., Renou, B. and Boukhalfa, A. M. "Laser-Induced Spark Ignition of Premixed Confined Swirled Flames." Combustion Science and Technology Vol. 185, No. 3 (2013): pp. 379-407. DOI 10.1080/00102202.2012.725791.

[17] Ahmed, Samer F. and Mastorakos, Epaminondas. "Spark ignition of lifted turbulent jet flames." Combustion and Flame Vol. 146, No. 1-2 (2006): pp. 215-231. DOI 10.1016/j.combustflame.2006.03.007.
[18] Ahmed, Samer F., Balachandran, Ramanarayan, Marchione, Teresa and Mastorakos, Epaminondas. "Spark ignition of turbulent nonpremixed bluff-body flames." Combustion and Flame Vol. 151, No. 1-2 (2007): pp. 366-385. DOI 10.1016/j.combustflame.2007.06.012.

[19] Ahmed, Samer F., Balachandran, Ramanarayan and Mastorakos, Epaminondas. "Measurements of ignition probability in turbulent non-premixed counterflow flames." Proceedings of the Combustion Institute Vol. 31 (2007): pp. 1507-1513. DOI 10.1016/j.proci.2006.07.089.

[20] Marchione, Teresa, Ahmed, Samer F. and Mastorakos, Epaminondas. "Ignition of turbulent swirling n-heptane spray flames using single and multiple sparks." Combustion and Flame Vol. 156, No. 1 (2009): pp. 166-180. DOI 10.1016/j.combustflame.2008.10.003.

[21] Worth, Nicholas A. and Dawson, James R. "Self-excited circumferential instabilities in a model annular gas turbine combustor: Global flame dynamics." Proceedings of the Combustion Institute Vol. 34, No. 2 (2013): pp. 3127-3134. DOI 10.1016/j.proci.2012.05.061.

[22] Worth, Nicholas A. and Dawson, James R. "Modal dynamics of self-excited azimuthal instabilities in an annular combustion chamber." Combustion and Flame Vol. 160, No. 11 (2013): pp. 2476-2489. DOI 10.1016/j.combustflame.2013.04.031.

[23] Allison, Patton M. and Mastorakos, Epaminondas. "Forced Response of Flames in a Bluff-Body Stabilized Annular Combustor." 55th AIAA Aerospace Sciences Meeting: pp. 1-12. 2017. American Institute of Aeronautics and Astronautics, Reston, Virginia. DOI 10.2514/6.2017-1337.

[24] Ciardiello, Roberto, Skiba, Aaron W., Gordon, Robert L. and Mastorakos, Epaminondas. "Experimental assessment of the lean blow-off in a fully premixed annular combustor." Experimental Thermal and Fluid Science Vol. 112 (2020): p. 109994. DOI https://doi.org/10.1016/j.expthermflusci.2019.109994. In press.

[25] Mularz, Edward J. "Lean, premixed, prevaporized combustion for aircraft gas turbine engines." 15th Joint Propulsion Conference: pp. 1-12. 1979. DOI 10.2514/6.1979-1318.

[26] Hayashi, Shigeru. "Compatibility Between Low-NOx Emissions and High-Combustion Efficiency by Lean Direct Injection Combustion." Volume 3: Coal, Biomass and Alternative Fuels; Combustion and Fuels; Oil and Gas Applications; Cycle Innovations. Turbo Expo: Power for Land, Sea, and Air: pp. 1-10. 1995. DOI 10.1115/95-GT-276.

[27] Foust, Michael, Thomsen, Doug, Stickles, Richard, Cooper, Clayton and Dodds, Will. "Development of the GE Aviation Low Emissions TAPS Combustor for Next Generation Aircraft Engines." 50th AIAA Aerospace Sciences Meeting including the New Horizons Forum and Aerospace Exposition: pp. 1-9. 2013. DOI 10.2514/6.2012-936.

[28] Kariuki, James, Dawson, James R. and Mastorakos, Epaminondas. "Measurements in turbulent premixed bluff body flames close to blow-off." Combustion and Flame Vol. 159, No. 8 (2012): pp. 2589-2607. DOI 10.1016/j.combustflame.2012.01.005. 
[29] Cordier, Matthieu, Vandel, Alexis, Renou, Bruno, Cabot, Gilles, Boukhalfa, Abdelkrim Mourad and Cazalens, Michel. "Spark Ignition of Confined Swirled Flames: Experimental and Numerical Investigation." Volume 1A: Combustion, Fuels and Emissions: pp. 1-12. 2013. American Society of Mechanical Engineers. DOI 10.1115/GT2013-
94384.

[30] Gaydon, Alfred Gordon and Wolfhard, Hans G. Flames, their structure, radiation, and temperature. Halsted Press (1979). 